\title{
The Mediating Role of Work-related Musculoskeletal Disorders on the Relationship between Psychosocial Factors and Presenteeism among Administrative Workers
}

\author{
Mohd Zulkifli Abdullah, Abdul Kadir Othman, and Maria Justine
}

\begin{abstract}
In a highly demanding working environment, the problem of work-related musculoskeletal disorders (WRMDs) is getting more serious as compared to previous days. This phenomenon brings significant negative effect on the productivity of the employees. Therefore, the present study was conducted to investigate the factors that contribute to the prevalence of WRMDs and to examine the influence of WRMDs on employees' presenteeism. Analyzing a total of 368 responses collected from the administrative employees, the findings indicate that the prevalence of WRMDs among administrative workers includes neck disorder $(67.1 \%)$, shoulders' disorder (73.4\%), upper-back disorder $\mathbf{( 7 0 . 1 \% )}$ and wrists/hands' disorder $(41.0 \%)$. The study also found that shoulders' and upper-back disorders partially mediate the relationship between social support and personal risk factors and presenteeism, neck and wrists/hands' disorders serve as partial mediators in the relationship between personal risk factors and presenteeism. The implication of the study is discussed.
\end{abstract}

Index Terms-Psychosocial factors, work-related musculoskeletal disorders, presenteeism.

\section{INTRODUCTION}

Productivity is an important indicator of economic growth and social health. It is vital to identify key factors that describe workers' health in their workplace and life [1] so that they can make a significant contribution to productivity. The indicator of worker productivity (index) could be measured by using absenteeism, disability (consisting of scattered illness and short-term disability absences) and presenteeism [2]. In the previous studies, the prevalence of sickness presenteeism and the impact on worker productivity were estimated.

A study among workers in a trade company found that $7 \%$ of them experienced health problems while being at work, with an estimated productivity loss of $13 \%$ per worker with health problems [3]. Among computer users, 8\% reported reduced productivity due to WRMDs with the mean productivity loss of $15 \%$ for women and $13 \%$ for men [4].

The effects of WRMDs on workers' productivity have

Manuscript received August 6, 2014; revised October 18, 2014.

Mohd Zulkifli Abdullah is with the Faculty of Business Management, Universiti Teknologi MARA Pahang, 26400 Malaysia (e-mail: mohdzulkifli_ha@yahoo.com).

Abdul Kadir Othman is with the Faculty of Business Management, Universiti Teknologi MARA Shah Alam, Selangor, Malaysia (e-mail: abdkadir@salam.uitm.edu.my).

Maria Justine is with the Faculty of Health Science, Universiti Teknologi MARA Puncak Alam, 42300 Puncak Alam, Malaysia (e-mail: maria205@salam.uitm.edu.my). been a common subject in previous studies [4]-[7]. However, these studies have been mostly conducted in a manufacturing context. Limited effort has been allocated in studying this issue in the administrative office environment.

People who work in the office environment are among those most likely to suffer from lower-back pain and neck stiffness due to long hours of sitting with very little movement [8]. In Malaysia, the Social Security Organization (SOCSO) reported that the number of cases involving musculoskeletal injuries is very high at 10,000 per year [9]. Over the years, computer-based technology has increased work intensity and created stressful, uncomfortable and unhealthy working environments inadvertently leading to an increase in WRMDs. Subsequently, it can significantly affect occupational functions of all performance areas since the upper body, neck, back and hands are vital parts of the body [10].

WRMDs are disorders of the nerves, tendons, muscles, and supporting structures and tissues of the body that result from workplace conditions or exposures [11], [12]. WRMDs are common health problems throughout the industrialized world and they are the major causes of disability among people under 45 years of age and the most expensive work-related disability, in terms of worker compensations, medical expenses and lost productivity [13].

Although WRMDs have been shown to have resulted primarily from physical load or stress from biomechanical forces in the body induced by job tasks, there is increasing evidence that WRMDs may be worsened by psychosocial factors [11], [14], [15]. Psychosocial factors refer to the perceptions or beliefs that workers have about the way their work environment is organized [16], [17]. These psychosocial factors are often referred to as work factors or job stressors [18]-[22]. Psychosocial factors are becoming an integral part of recent epidemiologic studies on WRMDs as identified by the National Institute of Occupational Safety and Health and the Research Council and Institute of Medicine [15], [21]. In the late 1990s and early 2000s, several epidemiological studies presented evidence for associations between WRMDs andseveral physical, psychosocial and individual factors [23], [24]. In the early 1990s, studies have focused on psychosocial factors of decision latitude and lack of co-worker support as factors contributing to upper-extremity WRMDs [25]. In 2001, a similar study by Leclerc, Landra, Chastang, Niedhammer and Roquilaure [26] found that lack of social support, time pressure and perceived workload to also associate with upper-extremity WRMDs. However, the lack of a universal definition and the difficulty in objectively measuring 
psychosocial factors has made it difficult to conduct studies to explore cause-and-effect in the context of WRMDs [27].

Therefore, this study attempts to investigate the mediating role of WRMDs on the link between psychosocial factors, which include job demand, decision latitude, social support, physical environment as well as personal risk factors and productivity among administrative workers. To accomplish the research objective of the study, one research question was developed, i.e., to what extent do WRMDs mediate the relationship between psychosocial factors and productivity among respondent?

\section{RESEARCH Methodology}

\section{A. Research Design}

The study is correlational in nature. The sampling frame is based on a list of office workers who hold the job position of administrative assistant-clerical and operation ( $\mathrm{N}-17)$, senior administrative assistant-clerical and operational (N-22), administrative assistant-financial (W-17) and senior administrative assistant-financial (W-22) from Universiti Teknologi MARA (UiTM) in Peninsular Malaysia. The size of the sample in this study is 393 . The respondents have been working full time in the office, spending over six hours per day at the workstation and working in the same position for the last 12 months.

\section{B. Instruments}

The questionnaire was adapted from the established questionnaire and the items were modified in order to get the required response to answer the research question. The questionnaire consists of several sections; namely, Section A concerns with the demographic information of respondents such as age, gender, marital status, work position and work experience. Section $B$ focuses on measuring the administrative workers' perceptions and experiences toward their psychosocial factors. In this study, five psychosocial factors were analyzed i.e. job demand, decision latitude, social support, physical environment and personal risk factors. Psychosocial factors were measured using a questionnaire taken from the Job Content Questionnaire (JCQ) [28], [29].

Section $\mathrm{C}$ focuses on measuring the prevalence of WRMDs (neck, shoulders, upper-back and wrists/hands) among respondents. The survey is a shortened version of the Nordic Musculoskeletal Symptom Survey. Previous studies have reported the validity of Nordic Questionnaire in assessing WRMDs [30], [31]. Finally, section D focuses on measuring productivity i.e. presenteeism using the Quantity and Quality (QQ) instruments [32], [33].

The questionnaire utilized closed-ended questions with a fixed range of possible answers utilizing a 5-point Likert scale with the following values; 1 = strongly disagree, 2 = disagree, $3=$ uncertain, $4=$ agree and $5=$ strongly agree to measure psychosocial factors in section B. Besides, a 5-point Likert scale with the following values; $1=$ never, $2=$ almost never, 3 = sometimes, $4=$ fairly often and $5=$ very often was used to measure absenteeism in section D. Questions on WRMDs symptoms used "yes" or "no" types of response.

\section{Data Analysis}

The data were analyzed using the SPSS Version 20. The study utilized both descriptive and inferential statistics. The descriptive statistics include mean and standard deviation. Besides, the hierarchical multiple regression (also known as sequential regression) analysis was used to test the mediating roles of WRMDs on the relationship between psychosocial factors and presenteeism.

\section{Profile of Respondents}

The analysis indicates that $68.8 \%$ were female and $31.3 \%$ were male participants. Most of them, $25 \%$, were from the age group of $25-30$ years old, followed by $24.5 \%$ in the age group of $31-35$ years old, $14.1 \%$ of them from the age group of $46-50,12.8 \%$ of them were above 50 years of age, $11.1 \%$ in the age group of $36-40$ years and $8.2 \%$ from were from the age group of $41-45$ years. However, only $4.3 \%$ of the respondents were under 25 years of age. Besides, most of the respondents had SPM for their highest education level (59.2\%), $14.3 \%$ had Diploma, $10.3 \%$ of them had STPM and $4.1 \%$ had a Bachelor Degree and only $2.2 \%$ had skills Certificate. For the current job position, $56.3 \%$ of the respondents worked as an Administrative Assistant-Clerical and Operation (N17), 19\% were Senior Administrative Assistant-Clerical and Operation (N22), 15.8\% were Administrative Assistant-Finance (W17) and 9\% were Senior Administrative Assistant-Finance (W22).

In the context of the respondents' experience in their current position at the workplace, it was found that 112 (30.4\%) had been working for $6-10$ years and 109 (29.6\%) had working experience of $1-5$ years. Besides, 82 respondents $(22.3 \%)$ had been working for more than 20 years while $39(10.6 \%)$ had $11-15$ years of experience and only a minority of them, that is, $14(3.8 \%)$ of them had been working for $16-20$ years and $12(3.3 \%)$ had less than 1 year working experience. With regard to marital status, majority of the respondents that were represented by 306 respondents $(832 \%)$ were married, $52(14.1 \%)$ were single and only 10 $(2.7 \%)$ were divorced.

\section{RESUlTS}

A total of 393 sets of questionnaires were distributed and were personally collected from the respective respondents. After three months, 368 questionnaires were collected. This is equivalent to the response rate of $93.6 \%$. The result shows that the prevalence of WRMDs as reported by administrative workers during the last 12 months includes neck disorder (67.1\%), shoulders' disorder (73.44\%), upper-back disorder (70.1\%) and wrists/hands' disorder (41.0\%).

Table I provides the summary of the mediating role of neck disorder on the relationship between Psychosocial Factors and Productivity i.e. Presenteeism. $\mathrm{R}^{2}$ changes of 0.047 indicate that neck disorder explains an additional $4.7 \%$ of the variance in Presenteeism, after the effects of Psychosocial Factors have been controlled for. It means that the inclusion of neck disorder increases the explanation of variance in Presenteeism by $4.7 \%$. This addition to the effect size is, by no means, small [34]. 
TABLE I: SUMMARY OF THE MEDIATING ROLE OF WRMDS (NECK DISORDER) ON THE RELATIONSHIP BETWEEN PSYCHOSOCIAL FACTORS AND PRODUCTIVITY (PRESENTEEISM)

\begin{tabular}{|c|c|c|c|}
\hline $\begin{array}{l}\text { Psychosocial Factors } \\
\text { \&WRMDs }\end{array}$ & $\begin{array}{l}\text { Presenteeism } \\
\text { Without } \\
\text { Mediator }\end{array}$ & $\begin{array}{l}\text { With } \\
\text { Mediator }\end{array}$ & Conclusion \\
\hline Job Requirement & 0.044 & 0.048 & Not a Mediator \\
\hline Decision Latitude & -0.038 & -0.040 & Not a Mediator \\
\hline Social Support & -0.112 & -0.101 & Not a Mediator \\
\hline Physical Environment & 0.007 & 0.007 & Not a Mediator \\
\hline Personal Risk Factors & $-0.210^{* *}$ & $-0.173 * *$ & Partial Mediator \\
\hline Neck & & $0.221 * * *$ & \\
\hline$R^{2}$ & 0.061 & 0.108 & \\
\hline Adjusted $R^{2}$ & 0.048 & 0.094 & \\
\hline$R$ Square Change & 0.061 & 0.047 & \\
\hline$F$ Change & 4.716 & 19.153 & \\
\hline Sig. $F$ Change & 0.000 & 0.000 & \\
\hline Durbin -Watson & & 2.034 & \\
\hline
\end{tabular}

This is a statistically significant contribution, as indicated by the significance $\mathrm{F}$ change $(F(5,362)=19.153, p=0.000)$. The result revealed that neck disorder was established to significantly mediate the relationship between Personal Risk Factors and Presenteeism $(\beta=-0.193, p<0.05)$. As can be seen in the above Table I, the beta value of Personal Risk Factors was reduced but still significant, therefore, it is concluded that neck disorder partially mediates the relationship between Personal Risk Factors and Presenteeism.

The summary of the mediating role of shoulders' disorder on the relationship between Psychosocial Factors and Presenteeism is presented in Table II. $R^{2}$ changes of 0.127 pointed out that shoulders' disorder explains an additional $12.7 \%$ of the variance in Presenteeism, even when the effects of Psychosocial Factors are statistically controlled for. The inclusion of shoulders' disorder increases the explanation of variance in Presenteeism by $12.7 \%$.

This is a statistically significant contribution, as shown by the significance $F$ change $(F(5,362)=33.548, p=0.000)$. The result indicates that shoulders' disorder was established to significantly mediate the relationship between Social Support and Presenteeism $(\beta=-0.122, p<0.01)$ and Personal Risk Factors and Presenteeism $(\beta=-0.161, p<0.05)$. As illustrated in Table II, there was a non-significant correlation between Social Support and Presenteeism $(\beta=-0.112, p>$ 0.05), however, Social Support showed a significant relationship with Presenteeism $(\beta=-0.122, p<0.01)$ when the shoulders' disorder served as a mediating variable. Therefore, shoulders' disorder is a partial mediating variable in the relationship between Social Support and Presenteeism. Besides, the beta value of Personal Risk Factors was reduced but still significant, therefore, it is summarized that shoulders' disorder partially mediates the relationship between Personal Risk Factors and Presenteeism.

TABLE II: SUMMARY OF THE MEDIATING ROLE OF WRMDS (SHOULDERS) ON THE RELATIONSHIP BETWEEN PSYCHOSOCIAL FACTORS AND PRODUCTIVITY (PRESENTEEISM)

\begin{tabular}{|c|c|c|c|}
\hline \multirow{2}{*}{$\begin{array}{l}\text { Psychosocial Factors } \\
\text { \&WRMDs }\end{array}$} & \multicolumn{3}{|c|}{ Presenteeism } \\
\hline & $\begin{array}{l}\text { Without } \\
\text { Mediator }\end{array}$ & $\begin{array}{l}\text { With } \\
\text { Mediator }\end{array}$ & Conclusion \\
\hline Job Requirement & 0.044 & 0.035 & Not a Mediator \\
\hline Decision Latitude & -0.038 & -0.052 & Not a Mediator \\
\hline Social Support & -0.112 & $-0.122^{*}$ & Partial Mediator \\
\hline Physical Environment & 0.007 & 0.031 & Not a Mediator \\
\hline Personal Risk Factors & $-0.210^{* *}$ & $-0.161 * *$ & Partial Mediator \\
\hline Shoulders & & $0.288 * * *$ & \\
\hline$R^{2}$ & 0.061 & 0.141 & \\
\hline Adjusted $R^{2}$ & 0.048 & 0.127 & \\
\hline$R$ Square Change & 0.061 & 0.080 & \\
\hline$F$ Change & 4.716 & 33.548 & \\
\hline Sig. $F$ Change & 0.000 & 0.000 & \\
\hline Durbin -Watson & & 2.036 & \\
\hline
\end{tabular}

Table III shows the summary of the mediating role of upper-back disorder on the relationship between Psychosocial Factors and Presenteeism. $\mathrm{R}^{\mathbf{2}}$ changes of 0.062 indicated that the upper-back disorder explains an additional $6.2 \%$ of the variance in Presenteeism, after the effects of Psychosocial Factors have been controlled for. It shows that the inclusion of upper-back disorder increases the explanation of variance in Presenteeism by $6.2 \%$.

This is a statistically significant contribution, as shown by the significance $F$ change $(F(5,362)=25.381, p=0.000)$. The results pointed out that the upper-back disorder was established to significantly mediate the relationship between Social Support and Presenteeism $(\beta=-0.126, p<0.01)$ and Personal Risk Factors and Presenteeism $(\beta=-0.171, p<$ $0.05)$. As can be seen, there was a non-significant correlation between Social Support and Presenteeism $(\beta=-0.112, p>$ 0.05), however, Social Support showed a significant relationship with Presenteeism $(\beta=-0.126, p<0.01)$ when the upper-back disorder served as mediating variable. Therefore, upper-back disorder serves a partial mediating variable in the relationship between Social Support and Presenteeism. Meanwhile, the beta value of Personal Risk Factors was reduced but still significant, therefore, it is concluded that upper-back disorder partially mediates the relationship between Personal Risk Factors and Presenteeism.

Table IV presents the summary of the mediating role of wrists/hands' disorder on the relationship between Psychosocial Factors and Presenteeism. $R^{2}$ changes of 0.081 explain that wrists/hands' disorder describes an additional $8.1 \%$ of the variance in Presenteeism, after the effects of Psychosocial Factors have been controlled for. It can be 
interpreted that the inclusion of wrists/hands' disorder increases the explanation of variance in Presenteeism by $8.1 \%$.

TABLE III: SUMMARY OF THE MEDIATING ROLE OF WRMDS (UPPER-BACK) ON THE RELATIONSHIP BETWEEN PSYCHOSOCIAL FACTORS AND PRODUCTIVITY (PRESENTEEISM)

\begin{tabular}{|c|c|c|c|}
\hline $\begin{array}{l}\text { Psychosocial Factors } \\
\text { \&WRMDs }\end{array}$ & $\begin{array}{l}\text { Presentee } \\
\text { Without } \\
\text { Mediator }\end{array}$ & $\begin{array}{l}\text { With } \\
\text { Mediator }\end{array}$ & Conclusion \\
\hline Job Requirement & 0.044 & 0.040 & Not a Mediator \\
\hline Decision Latitude & -0.038 & -0.007 & Not a Mediator \\
\hline Social Support & -0.112 & $-0.126^{*}$ & Partial Mediator \\
\hline Physical Environment & 0.007 & 0.017 & Not a Mediator \\
\hline Personal Risk Factors & $-0.210^{* *}$ & $-0.171 * *$ & Partial Mediator \\
\hline Upper-Back & & $0.288 * * *$ & \\
\hline$R^{2}$ & 0.061 & 0.123 & \\
\hline Adjusted $R^{2}$ & 0.048 & 0.108 & \\
\hline$R$ Square Change & 0.061 & 0.062 & \\
\hline$F$ Change & 4.716 & 25.381 & \\
\hline Sig. $F$ Change & 0.000 & 0.000 & \\
\hline Durbin -Watson & & 2.002 & \\
\hline
\end{tabular}

TABLE IV: SUMMARY OF THE MEDIATING ROLE OF WRMDS (WRISTS/HANDS) ON THE RELATIONSHIP BETWEEN PSYCHOSOCIAL FACTORS AND PRODUCTIVITY (PRESENTEEISM)

\begin{tabular}{|c|c|c|c|}
\hline \multirow{2}{*}{$\begin{array}{l}\text { Psychosocial Factors } \\
\text { \&WRMDs }\end{array}$} & \multicolumn{3}{|c|}{ Presenteeism } \\
\hline & $\begin{array}{l}\text { Without } \\
\text { Mediator }\end{array}$ & $\begin{array}{l}\text { With } \\
\text { Mediator }\end{array}$ & Conclusion \\
\hline Job Requirement & 0.044 & 0.042 & Not a Mediator \\
\hline Decision Latitude & -0.038 & -0.054 & Not a Mediator \\
\hline Social Support & -0.112 & -0.083 & Not a Mediator \\
\hline Physical Environment & 0.007 & -0.004 & Not a Mediator \\
\hline Personal Risk Factors & $-0.210 * *$ & $-0.174 * *$ & Partial Mediator \\
\hline Wrists/Hands & & $0.288 * * *$ & \\
\hline$R^{2}$ & 0.061 & 0.142 & \\
\hline Adjusted $R^{2}$ & 0.048 & 0.128 & \\
\hline$R$ Square Change & 0.061 & 0.081 & \\
\hline$F$ Change & 4.716 & 34.108 & \\
\hline Sig. $F$ Change & 0.000 & 0.000 & \\
\hline Durbin -Watson & & 1.975 & \\
\hline
\end{tabular}

This is a statistically significant as indicated by the significance $F$ change $(F(5,362)=34.108, p=0.000)$. The result showed that wrists/hands' disorder was established to significantly mediate the relationship between Personal Risk Factors and Presenteeism $(\beta=-0.174, p<0.05)$. As also shown in the Table IV, the beta value of Personal Risk Factors was reduced but still significant, therefore, it is summarized that wrists/hands' disorder serves as a partial mediating variable in the relationship between Personal Risk Factors and Presenteeism.

\section{DISCUSSION}

The prevalence of WRMDs among administrative workers during the last 12 months especially shoulders (73.4\%), upper-back $(70.1 \%)$ and neck $(67.1 \%)$ was very high. This is consistent with findings from previous studies [27], [31]. After reviewing more than 31 studies associated to posture-induced musculoskeletal disorders in various industries, the U.S. Department of Health and Human Services [11] concluded that there is strong evidence and verification of the relationship between static and/or extreme postures and WRMDs mainly neck and shoulders. Besides, in Malaysia and Singapore, Lin's (1991) study of 903 women workers from five semiconductor factories found that workers with the major problems regarding musculoskeletal disorders complained of having back and shoulder disorders as well as hand and arm pains [37].

It is noticeable from the results that neck disorder serves as a partial mediator in the relationship between personal risk factors and presenteeism. The results indicate that personal risk factors such as an involvement in a serious accident or an operation previously and exposure on WRMDs in family members contribute to neck disorder and affect presenteeism. The present findings are consistent with other research which found the significant relationships among personal risk factors, neck disorder and presenteeism [38]. Besides, the results revealed that shoulders and upper-back disorders partially mediate the relationship between social support and personal risk factors and presenteeism. Low social support from supervisor and coworkers' contribute to shoulders and upper-back disorders, consequently affecting the work presenteeism. The findings of the current study are constant with other studies that found low social support were related to increased risk of neck, shoulder, and upper-back pain [39]. Furthermore, previous studies proved that workers with elbow and shoulder disorders worked reduced hours of their working time [40].

Moreover, wrists/hands' disorder serves as a significant contributor as a mediator in the relationship between personal risk factors and presenteeism. This study confirms that personal risk factors (for example, previous experiences of WRMDs, medical conditions, and leisure time activities) also play an important role in musculoskeletal disorders including wrists/hands' disorder and therefore should be equally monitored [41]. Besides, musculoskeletal pain is a commonly studied health condition that has been associated with impaired presenteeism [42].

Overall, the findings of this study provide support for the 
outcomes of the previous research. For example, previous studies in the early 2000's among women workers in the Semiconductor Industry in Peninsular Malaysia highlighted the effect of psychosocial factors in increasing the risk of musculoskeletal problems such as neck and shoulder pain [43], [44] upper-limb disorders, particularly wrists/hands' disorder [45] and upper-back disorder [46].

Contrary to expectations, this study did not find significant relationships between certain factors that include job demand, decision latitude and physical environment and WRMDs. For example, previous studies revealed that high job demands, low social support, time pressure, monotonous or repetitive work and low job satisfaction have been identified as risk factors for musculoskeletal disorders of the neck and upper-extremity [11], [47], [48]. A study conducted by Kjellberg and Wadman in 2007 concluded that psychosocial work conditions such as high job demand and social support were related to shoulder and neck pain, respectively [49].

\section{CONCLUSION}

As a conclusion, the prevalence of WRMDs among administrative workers during the last 12 months especially shoulders (73.4\%), upper-back (70.1\%) and neck (67.1\%) was very high. The results indicate that most of them had suffered from WRMDs mainly the shoulders, upper-back and neck disorders. Besides, this study shows that neck disorder serves a partial mediating variable in the relationship between personal risk factors and presenteeism. It is also revealed that shoulders' and upper-back disorders are partially mediated the relationship between social support and personal risk factors and presenteeism. Furthermore, wrists/hands' disorder shows a significant value as a mediator in the relationship between personal risk factors and presenteeism. The most obvious finding emerged from this study is that personal risk factors are the strongest predictors associated with WRMDs and presenteeism. Besides, the study reflects that presenteeism is affected by WRMDs. However, the findings of the current study do not support the previous research that there is no significant relationship between certain factors that include job demands, decision latitude and physical environment and WRMDs and between these factors and presenteesim.

\section{A. Managerial Implications}

The findings of the present study pose several implications to managers. First, they have to be constantly aware of the psychosocial factors of their subordinates so that appropriate actions can be taken to avoid prolonged effects especially on their productivity i.e. presenteeism. Adequate educational information, health-related workshops, carefully structured work assignment, ergonomically arranged workspace and equipment and the use of ergonomically approved furniture and tools might be helpful in reducing the prevalence of WRMDs among administrative workers. Second, managers should continuously educate and motivate the workers on how to work effectively and efficiently through formal discussions, workshops, seminars, briefings, emails, flyers, brochures and others. Finally, managers should organize special programs to discharge stress among the subordinates such as family day, retreat, teambuilding or other programs that swift the workers' attention away from their work. All these measures can be utilized by managers to ensure that the workers' satisfaction level on psychosocial factors is at the contentment level and to prevent WRMDs.

\section{B. Suggestion for Future Research}

The current study provides the fundamental understanding of the mediating role of WRMDs between psychosocial factors and presenteeism among administrative workers. Besides, this study was conducted among those holding a job position of administrative assistant (clerical/operation and financial) in UiTM in Peninsular Malaysia. Future studies should be extensive using larger sample size and covering bigger population so that the findings might be generalized to an extended population. Using different methodology is highly recommended to accurately capture the information regarding psychosocial factors, WRMDs and presenteeism rather than relying on the perception of the respondents. The use of experimental groups for a specified time period (longitudinal study) is highly recommended.

\section{ACKNOWLEDGMENT}

The authors gratefully acknowledge the Ministry of Education and Universiti Teknologi MARA, Malaysia for funding this research.

\section{REFERENCES}

[1] R. Escorpizo, "Understanding work productivity and its application to work-related musculoskeletal disorders," International Journal of Industrial Ergonomics, vol. 38, pp. 291-297, 2008.

[2] W. N. Burton, D. J. Conti, C. Y. Chen, A. B. Schultz, and D. W. Edington, "The role of health risk factors and disease on worker productivity," Journal of Occupational and Environmental Medicine, vol. 41, pp. 863-877, 1999.

[3] W. B. F. Brouwer, M. A. Koopmanschap, and F. F. H. Rutten, "Productivity losses without absence: measurement validation and empirical evidence," Journal of Health Policy, vol. 48, pp. 13-27, 1999.

[4] M. Hagberg, E. W. Tornqvist, and A. Toomingas, "Self-reported reduced productivity due to musculoskeletal symptoms: associations with workplace and individual factors among white-collar computer users," Journal of Occupational Rehabilitation, vol. 12, pp. 151-162, 2002.

[5] F. Lotters, W. J. Meerding, and A. Burdorf, "Reduced productivity after sickness absence due to musculoskeletal disorders and its relation to health outcomes," Scandinavian Journal of Work, Environment and Health, vol. 31, pp. 367-374, 2005.

[6] D. E. Beaton and C. A. Kennedy, "The workplace upper extremity research group, beyond return to work: testing a measure of at-work disability in workers with musculoskeletal pain," Journal of Quality of Life Research, vol. 14, no. 8, pp. 1869-1879, 2005.

[7] G. Pransky, K. Benjamin, C. H. Fotouhi, K. E. Fletcher, J. Himmelstein, and J. N. Katz, "Work-related outcomes in occupational low back pain: a multidimensional analysis," Journal of Spine, vol. 27, no. 8, pp. 864-870, 2002.

[8] British Chiropractic Association (BCA). (2006). [Online]. Available: http://www.sciencebasedmedicine.org

[9] L. T. Lee, "Opening Address of Chairman, NIOSH Malaysia," in Proc. the Agriculture Ergonomics Development Conference, M. K. Halimahtun, Ed., Kuala Lumpur, Malaysia: IEA Press; p. 6. 2007.

[10] A. Z. Seyed and D. S. Indra, "The Relationship between psychosocia work factors, work stress and computer-related musculoskeletal discomforts among computer users in Malaysia," International Journal 
of Occupational Safety and Ergonomics, vol. 15, no. 4, pp. 425-434, 2009.

[11] B. P. Bernard. (May 2005). Musculoskeletal Disorders (MSMD) and Workplace Factors: A Critical Review of Epidemiologic Evidence for Work Related Musculoskeletal Disorders of the Neck, Upper Extremity, and Low Back. NIOSH Publication No. 97-141. Atlanta: Centers for Disease Control and Prevention. [Online]. Available: http://www.cdc.gov/niosh/docs/97-141

[12] A. L. Cohen, C. C. Gjessing, L. J. Fine, B. P. Bernard, and J. D. Mcglothlin, "Elements of ergonomics programs: a primer based on workplace evaluations of musculoskeletal disorders," National Institute for Occupational Safety and Health, Cincinnati, 1997.

[13] G. B. J. Andersson, "Epidemiologic features of chronic low-back pain," Lancet, vol. 354, pp. 581-585, 1999.

[14] S. J. Linton and M. Ryberg, "A cognitive-behavioral group intervention as prevention for persistent neck and back pain in a non-patient population: a randomized controlled trial," Journal of Pain vol. 90, pp. 83-90, 2001.

[15] National Research Council and Institute of Medicine Panel. (2001). $M$ Sculoskeletal Disorders and the Workplace, Commission on Behavioral and Social Sciences and Education, Musculoskeletal Disorders and the Workplace: Low Back and Upper Extremities. National Academy Press, Washington DC. [Online]. Available: http://www.nap.edu

[16] A. Toomingas, T. Theorell, H. Michelsen, R. Nordemarand, M. Srockholm, "Associations between self-rated psychosocial work conditions and musculoskeletal symptoms and signs," Scandinavian Journal of Work, Environment and Health, vol. 23, pp. 130-139, 1997.

[17] P. W. Buckle and J. J. Devereux, "The nature of work-related neck and upper limb musculoskeletal disorders," Journal of Applied Ergonomics, vol. 33, pp. 207-217, 2002.

[18] B. C. Amick, N. G. Swanson, and H. Chang, "Office technology and musculoskeletal disorders: building an ecological model," Journal of Occupational Medicine, vol. 14, pp. 97-112, 1999.

[19] G. D. Huang, M. Feuerstein, and S. L. Sauter, "Occupational stress and work-related upper extremity disorders: concepts and models," American Journal of Industrial Medicine, vol. 41, pp. 298-314, 2002.

[20] L. A. MacDonald, J. A. Deddens, B. Grajewski, E. A. Whelan, and J. J. Hurrell, "Job stress among female flight attendants," Journal of Occupational and Environmental Medicine, vol. 45, pp. 703-714, 2003.

[21] National Institute for Occupational Safety and Health (NIOSH), "The changing organization of work and the safety and health of working people: knowledge gaps and research directions," DHHS (NIOSH), Publication no. 16, National Institute for Occupational Safety and Health, Cincinnati, 2002.

[22] N. Warren, "Work stress and musculoskeletal disorder etiology: the relative roles of psychosocial and Physical Risk Factors," Journal of Prevention, Assessment and Rehabilitation, vol. 17, pp. 221-234, 2001.

[23] J. Malchaire, N. Cock, and S. Vergracht, "Review of the factors associated with musculoskeletal problems in epidemiological studies," International archives of occupational and environmental health, vol. 74, no. 2, pp. 79-90, 2001.

[24] M. Aptel, A. A. Cuvelier, and J. C. Cnockaert, "Work-related musculoskeletal disorders of the upper limb," Joint Bone Spine, vol. 69, no. 6 , pp. 546-555, 2002.

[25] J. Faucett and D. Rempel, "VDT - related musculoskeletal symptoms: Interactions between work posture and psychosocial work factors," American Journal of Industrial Medicine, vol. 26, no. 5, pp. 597-612, 1994.

[26] A. Leclerc, M. F. Landre, J. F. Chastang, I. Niedhammer, and Y. Roquelaure, "Upper-limb disorders in repetitive work," Scandinavian Journal of Work, Environment \& Health, vol. 27, no. 4, pp. 268-278, 2001.

[27] A. Descatha, Y. Roquelaure, J. F. Chastaq, B. Evanoff, M. Melchior, C. Mariot, C. Ha, E. Imberno, M. Goldberq, and A. Laclerc, "Validity of Nordic-style questionnaires in the surveillance of upper-limb work-related musculoskeletal disorder," Scand Journal of Work Environ Health, vol. 33, pp. 58-65, 2007.

[28] R. Karasek, C. Brisson, N. Kawakami, I. Houtman, P. Bongers, and B. Amick, "The job content questionnaire (JCQ): an instrument for internationally comparative assessments of psychosocial job characteristics," Journal of Occupational Health Psychology, vol. 3, pp. 322-355, 1998.

[29] J. Li, W. Yang, P. Liu, Z. Xu, and S. Cho, "Psychometric evaluation of the Chinese (mainland) version of job content questionnaire: a study in university hospitals," Journal of Industrial Health, pp. 260-267, 2004.
[30] K. Palmer, G. Smith, S. Kellingray, and C. Cooper, "Repeatability and validity of an upper limb and neck discomfort questionnaire: the utility of the standardized Nordic questionnaire," Occup Med, vol. 49, pp. 171-175, 1999.

[31] A. Burdorf, W. Post, and T. Bruggeling, "Reliability of a questionnaire on sickness absence with specific attention to absence due to back pain and respiratory complaints," Journal of Occup Environ Med, vol. 53, pp. 58-62, 1996.

[32] W. J. Meerdinga, W. Ijzelenberg, M. A. Koopmanschap, J. L. Severens, and A. Burdorf, "Health problems lead to considerable productivity loss at work among workers with high physical load jobs," Journal of Clinical Epidemiology, vol. 58, pp. 517-523, 2005.

[33] J. Cohen, "Qualitative methods in psychology: a power primer," Psychological Bulletin, vol. 112, no. 1, pp 155-159, 1992.

[34] N. G. Swanson and S. L. Sauter, "A multivariate evaluation of an office ergonomic intervention using longitudinal data," Theoretical Issues in Ergonomics Science, vol. 7, no. 1, pp. 3-17, 2006.

[35] A. C. Esser, J. G. Koshy, and H. W. Randle, Ergonomics in Office-Based Surgery: A Survey-Guided Observational Study by the American Society for Dermatologic Surgery, Inc.-Published by Blackwell Publishing, 2007, vol. 33, pp. 1304-1314.

[36] V. Lin, Health, Women's Work, and Industrialization: Semiconductor Workers in Singapore and Malaysia, New York and London, U.K, Garland Publishing, 1991.

[37] B. Cagnie, L. Danneels, D. V. Tiggelen, V. D. Loose, and D. Cambier, "Individual and work related risk factors for neck pain among office workers: a cross sectional study," Eur Spine J. vol. 16, no. 5, pp. 679-686, May 2007.

[38] P. Larsman and J. J. Hanse, "The impact of decision latitude, psychological load and social support at work on the development of neck, shoulder and low back symptoms among female human service organization workers," International Journal of Industrial Ergonomics, vol. 39, pp. 442-446, 2009.

[39] J. S. Roy, F. Desmeules, and J. C. MacDermid, "Psychometric properties of presenteeism scales for musculoskeletal disorders," Journal of Rehabilitation Medicine, vol. 43, no. 1, pp. 23-31, 2011.

[40] J. F. Thomsen, S. Mikkelsen, J. H. Andersen, N. Fallentin, I. P. Loft, P. Frost, A. Kaergaard, J. P. Bonde, and E. Overgaard, "Risk factors for hand- wrist disorders in repetitive work," Occup Environ Med., vol. 64, no. 8, pp. 527-533, 2007.

[41] M. Campo and A. R. Darragh, "Work-related musculoskeletal disorders are associated with impaired presenteeism in allied health care professionals," JOEM, vol. 54, no. 1, January 2012.

[42] B. Cassou, F. Derriennic, C. Monfort, J. Norton, and A. Touranchet, "Chronic neck and shoulder pain, age, and working conditions: longitudinal results from a large random sample in France," Journal of Occup Environ Med., vol. 59, pp. 537-544, 2002.

[43] A. Kaergaard and J. H. Andersen, "Musculoskeletal disorders of the neck and shoulders in female sewing machine operators: prevalence, incidence and prognosis," Journal of Occup Environ Med., vol. 57, pp. $528-534,2000$.

[44] J. J. Devereux, I. G. Vlachonikolis, and P. W. Buckle, "Epidemiological study to investigate potential interaction between physical and psychosocial factors at work that may increase the risk of symptoms of musculoskeletal disorder of the neck and upper limb," Journal of Occupational and Environmental Medicine, vol. 59, pp. 269-277, 2002.

[45] J. J. Devereux and P. W. Buckle, "Interactions between physical and psychosocial risk factors at work increase the risk of back disorders: an epidemiological approach," Journal of Occupational and Environmental Medicine, vol. 56, pp. 343-353, 1999.

[46] P. M. Bongers, C. R. D. Winter, M. A. J. Kompier, and V. H. Hildebrandt, "Psychosocial factors at work and musculoskeletal disease," Scandinavian Journal of Work, Environment and Health, vol. 19, pp. 297-312, 1993.

[47] G. A. M. Ariens, W. V. Mechelen, P. M. Bongers, L. M. Bouter, and G. V. D. Wal, "Psychosocial risk factors for neck pain: a systematic review," Am Journal of Ind Med, vol. 39, pp. 180-193, 2001.

[48] A. L. Cohen, C. C. Gjessing, L. J. Fine, B. P. Bernard, and J. D. Mcglothlin, "Elements of ergonomics programs: a primer based on workplace evaluations of musculoskeletal disorders," National Institute for Occupational Safety and Health, Cincinnati, 1997.

[49] A. Kjellberg and C. Wadman, "The role of the affective stress response as a mediator of the effect of psychosocial risk factors on musculoskeletal complaints-part 1: assembly workers," International Journal of Industrial Ergonomics, vol. 37, pp. 367-374, 2007. 
Mohd Zulkifli Abdullah is a senior lecturer at the Faculty of Business Management, Universiti Teknologi Mara, Pahang, Malaysia, specializing in the area of health administration. He is currently pursuing his $\mathrm{PhD}$ in health administration at UiTM Puncak Alam Campus.

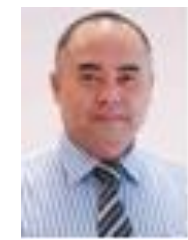

Abdul Kadir Othman is a senior lecturer at the Faculty of Business Management, Universiti Teknologi Mara, Shah Alam, Malaysia, specializing in the area of organizational psychology. He obtained his $\mathrm{PhD}$ in administrative science in 2010 from the same university. He is currently holding the position of head of the centre for postgraduate studies of the Faculty of Business Management. He has published a number of research articles and books in reputable publishes.

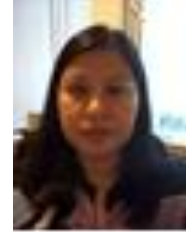

Maria Justine is a certified physiotherapist and currently hold a senior lecturer post at the Faculty of Health Science, Universiti Teknologi Mara, Puncak Alam Campus, Selangor Malaysia. She obtained her PhD in gerontology from UPM in 2010. Her research interests include geriatric and musculoskeletal rehabilitation. 